\title{
Angiographic profile of young patients ( $\leq 40$ years) in a tertiary care center of Nepal
}

\author{
Binay Kumar Rauniyar ${ }^{1}$, Arun Kadel ${ }^{2}$, Kiran Prasad Acharya², Kartikesh Thakur ${ }^{3}$, \\ Rakesh Bahadur Adhikari ${ }^{3}$, Deepak Limbü3 ${ }^{3}$ Sujeeb Rajbhandari ${ }^{4}$, Subodh Kansakar ${ }^{4}$, \\ Chandra Mani Adhikari', Arun Maskey", Rajib Rajbhandari", Rabi Malla ${ }^{4}$ \\ ${ }^{1}$ Cardiologist, Department of Cardiology, Shahid Gangalal National Heart Center, Nepal, ${ }^{2}$ Senior Resident, Department \\ of Cardiology, Shahid Gangalal National Heart Center, Nepal, ${ }^{3}$ Registrar, Department of Cardiology, Shahid Gangalal \\ National Heart Center, Nepal ${ }^{4}$ Senior Consultant Cardiologist, Department of Cardiology, Shahid Gangalal National \\ Heart Center, Nepal
}

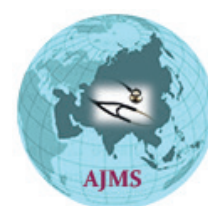

\section{A B S TRACT}

Background: With rise in prevalence of conventional risk factors like diabetes, hypertension, smoking, dyslipidemia and obesity the incidence of coronary artery disease in young patients have increased in the recent decades even in developing world. There have been multiple studies done in Nepal studying the angiographic profile of coronary disease in general population. However, only few studies has been done till date on the angiographic profile in the young population in our country. Aims and Objectives: In this study, we aim to determine the angiographic profile of young patient $\leq 40$ years in a tertiary care centre of Nepal. Materials and Methods: A retrospective analytic study was done in Shahid Gangalal National Heart Centre from January 2019 to December 2019. Individuals of both genders with age $\leq 40$ years who underwent coronary angiography were included. Results: Total 109 patients were included. Out of 109, 89 were male and 20 were female. The mean age for male was $35.55 \pm 4.31$ and for female was $38.55 \pm 1.90(P=0.003)$. Among 61 $(55.96 \%)$ patients who had significant coronary artery disease, 33 patients $(30.27 \%)$ with single vessel disease, 15 patients $(13.76 \%)$ had double vessel disease, and 13 patients $(11.92 \%)$ had triple vessel disease. Left anterior descending (LAD) artery was found to be most frequently involved in all patterns of Coronary artery disease (CAD). Smoking was the most common coronary risk factor present in $29.3 \%$ of patients followed by hypertension, family history of premature CAD and diabetes in $14.6 \%, 7.5 \%$ and $5.5 \%$ of patients respectively. Overall, the prevalence of smoking was more in males $(31.4 \%)$ than in females (20\%). Conclusion: Single vessel disease (SVD) was most prevalent in young patients with significant CAD. LAD is the most commonly involved coronary artery followed by Right coronary artery (RCA) and Left Circumflex (LCX).

Key words: Coronary arterial disease; Coronary angiographic profile; Risk factors; Young Adult

\section{INTRODUCTION}

Coronary artery disease (CAD) is the leading cause of mortality and morbidity worldwide. ${ }^{1}$ Because of higher risk factor levels at younger ages, South Asian have higher incidence of coronary artery disease globally. ${ }^{2}$ Coronary artery diseases usually manifest clinically in middle and older age groups, the incidence of coronary artery disease in less than 40 years of age is reported to be between $3-6 \%$ of the coronary population. The short-term prognosis and functional status of young patients with CAD is excellent. ${ }^{3,4}$ Prevalence of CAD in young adults and adolescents has been shown to be increased with rise in prevalence of conventional risk factors like diabetes, Hypertension, smoking, dyslipidemia and obesity. ${ }^{5}$ Young patients are at increased risk to be misdiagnosed 
since they do not frequently have traditional coronary risk factors. ${ }^{6}$ Angiographic studies also showed major differences with higher incidence of normal coronary arteries, mild luminal irregularities, and single vessel coronary artery disease. ${ }^{7}$

There is limited data available concerning the characterization of coronary arterial lesions by coronary angiography on young adults in Nepal. So, this study was conducted to assess the angiographic characteristics of coronary artery disease in young Nepalese patients.

\section{MATERIALS AND METHODS}

One hundred and nine patients presented to Cardiology Department of Shahid Gangalal National Heart Centre (SGNHC) and underwent coronary angiography from January 2019 to December 2019 were retrospectively analyzed. Patients $\leq 40$ years with ST segment elevation MI (STEMI), Non-ST segment elevation MI (NSTEMI) and Unstable Angina according to American College of Cardiology/American Heart Association (ACC/AHA) definitions and treated as per ACC/AHA recommendations (ACC/AHA Guidelines for the Management of Patients With ST-Elevation Myocardial Infarction; 2014 AHA/ ACC Guideline for the Management of Patients With Non-ST-Elevation Acute Coronary Syndromes ) as well as with non-invasive evidence of LV systolic dysfunction, heart failure and sign of ischemia after exercise stress test and those patients are planned for cardiac valve surgery who underwent Coronary angiography in SGNHC were included.

Demographic data e.g. age, gender as well as coronary angiography findings were recorded on the proforma. Significant CAD was defined as the presence of $>50 \%$ stenosis of any of the epicardial vessels. Patients with non-critical coronary was defined as $<50 \%$ stenosis in any of the epicardial vessels. Normal vessels were defined as the complete absence of any disease in the left main coronary artery (LMCA), left anterior descending (LAD), right coronary artery (RCA), and left circumflex (LCX) as well as in their main branches (diagonal, obtuse marginal, ramus intermedius, posterior descending artery, and poster lateral branch). Patients were classified as having singlevessel disease (SVD), double-vessel disease (DVD) or triple vessel disease (TVD) accordingly.

The results were reported as mean \pm standard deviation for the quantitative variables and percentages for the categorical variables. $\mathrm{P}<0.05$ was considered as statistically significant. All the collected data was stored in an electronic database (MS-Excel Sheet) and the statistical analyses were carried out via statistical software (SPSS 22.0 for Windows).

\section{RESULTS}

As the incidence of presenting female is less than male, among 109 patients (range 25 - 40 years) majority were male $89(81.65 \%)$ and $20(18.35 \%)$ were female. The mean age for male was $35.55 \pm 4.31$ and for female was 38.55 $\pm 1.90(\mathrm{p}=0.003)$. Baseline characteristics are mentioned in Table 1.

Among the young patients who underwent coronary angiography smoking was the most common coronary risk factor present in $29.3 \%$ of patients. Overall, the prevalence of smoking was more in males $(31.4 \%)$ than in females $(20 \%)$. This was followed by hypertension, family history of premature $\mathrm{CAD}$ and diabetes in $14.6 \%, 7.5 \%$ and $5.5 \%$ of patients respectively as shown in Table 2 .

As revealed by the coronary angiography, among 109 patients, $61(55.96 \%)$ patients had significant coronary artery disease, while $13(11.92 \%)$ patients had nonsignificant coronary artery stenosis and 35 (32.11\%) patients had normal coronaries. Among those 61 patients with significant coronary artery stenosis, 33 patients (30.27\%) with single vessel disease, 15 patients $(13.76 \%)$ had double vessel disease, and 13 patients $(11.92 \%)$ had triple vessel disease as shown in Table 3. None of them had disease in the left main stem.

LAD was found to be most frequently involved in all patterns of CAD, whether SVD, DVD or TVD. A total of 46 lesions $(75.40 \%)$ occurred in LAD, followed by 29 lesions $(47.50 \%)$ in RCA, $25(40.98 \%)$ in left circumflex, and 2 lesions (3.27\%), Ramus Intermedius as shown in Table 4.

\begin{tabular}{lc}
\multicolumn{2}{l}{ Table 1: Demographic profile of patients } \\
\hline Various Parameters & Baseline values \\
\hline Age (years) & $36.1 \pm 4.15$ \\
Male $(\mathrm{n}$ and $\%)$ & $89(81.65 \%)$ \\
Female ( $\mathrm{n}$ and $\%)$ & $20(18.35 \%)$ \\
Age group $(<25$ years) & $18(17 \%)$ \\
Age group $(25-40$ years & $91(83 \%)$ \\
\hline
\end{tabular}

\begin{tabular}{lc} 
Table 2: Risk factor profile of patients $(\mathbf{n = 1 0 9 )}$ \\
\hline Coronary risk factors & $\mathbf{n}(\%)$ \\
\hline Hypertension & $16(14.6 \%)$ \\
Diabetes & $6(5.5 \%)$ \\
Smoking & $32(29.3 \%)$ \\
Family history of premature CAD & $8(7.5 \%)$ \\
\hline
\end{tabular}




\begin{tabular}{|c|c|c|c|c|c|}
\hline $\begin{array}{l}\text { Extent of } \\
\text { Disease }\end{array}$ & SVD & DVD & TVD & $\begin{array}{c}\text { Non- } \\
\text { significant }\end{array}$ & Normal \\
\hline Number & 33 & 15 & 13 & 13 & 35 \\
\hline Percentage & 30.27 & 13.76 & 11.92 & 11.92 & 32.11 \\
\hline
\end{tabular}

\begin{tabular}{|c|c|c|c|c|c|}
\hline Coronary artery involvement & LAD & RI & LCX & RCA & LM \\
\hline Frequency & 46 & 2 & 25 & 29 & 0 \\
\hline Percentage & 75.40 & 3.27 & 40.98 & 47.54 & 0 \\
\hline
\end{tabular}

\section{DISCUSSION}

On studying the pattern of coronary arterial involvement in our study patients, we came across a relatively high frequency of angiographically normal coronary arteries, more than one third of the total study population similar as in study carried out in Pakistan. ${ }^{8}$ One reason regarding this important finding with the high incidence of angiographically normal coronary arteries in young patients may be our study also includes pre-operative coronary angiography in those patients who are going for valve replacement surgery.

There is paucity of data in literature regarding the characteristics of angiographic stenosis morphologic features in young patients. Angiographically, the incidence of one vessel disease and normal or minimal lesion coronary anatomy were more frequent in the young patients and incidence of multi-vessel disease were more frequent in the elderly patients. While, Saghir T et al showed greater percentage of young patient had significant CAD, ${ }^{9}$ but Young patients with significant coronary artery obstruction show less extensive disease than patient of old age group. ${ }^{9-10}$ Angiographically, the incidence of one vessel disease and normal or minimal lesion coronary anatomy were more frequent in the young patients and incidence of multi-vessel disease were more frequent in the elderly patients. ${ }^{10}$ The skewed gender distribution (males $81.65 \%$ versus females $18.35 \%$ ) of the study population can be attributed to the gender bias and atypical presentation, which is also a feature in other South Asian studies. ${ }^{10-12}$ This can be attributed to gender disparity and inequality in tertiary healthcare facility in Nepali society.

Single-vessel involvement was most prevalent, followed by double-vessel and triple vessel similar to Saghir T et al. study ${ }^{10}$ and Hong MK et al. study. ${ }^{13}$ SVD was also most commonly involved in male as well as female patients followed by DVD, and TVD with statistical significance similar to Saghir T et al. study. ${ }^{10}$ Similar to previous studies, no significant occlusions of the left main coronary artery were seen in our study. ${ }^{14}$ Different studies conducted in different countries showed LAD was most frequently affected followed by RCA and LCX. ${ }^{12-14}$ similarly in our study, $75 \%$ of CAD cases had LAD lesion.

Family history emerged as a most common risk factor associated with CAD in young individuals ${ }^{15}$ but, beside family history, Major coronary disease risk factors like age, serum cholesterol level, systolic blood pressure, and cigarette smoking, many of which are modifiable, are strong contributors to prediction of future risk, even in young men. We can prevent major cardiovascular events by formulating appropriate strategies to identify young men at heightened risk for death from coronary heart disease in later adulthood. ${ }^{16}$

\section{CONCLUSION}

The rapid changes in lifestyle, unhealthy habits e.g. smoking, sedentary life style etc., dietary factors, economic development and higher prevalence of diabetes and hypertension are considered to be responsible for the increase of coronary artery disease in young adult. Overall SVD was most prevalent in young patients with significant CAD. LAD is the most commonly involved coronary artery followed by RCA and LCX.

Though large scale survey and clinical research should be conducted to determine the different aspects of CAD in Nepal, at the end of this study for primary and secondary prevention strategies of CAD in young, we recommend early risk stratification, identification of the disease and its management to prevent fatal outcomes in a large number of cases.

In addition the study of novel risk factors including Highly sensitive C-reactive protein (hsCRP), Homocysteine, Fibrinogen, small dense Low Density Lipoprotein (sdLDL), Apolipoprotein A1 (Apo A1), Apolipoprotein B (Apo B) and Lipoprotein (a) $\{\mathrm{Lp}(\mathrm{a})\}$ needs to be done in all young patients with coronary artery disease who lack conventional risk factors.

\section{REFERENCES}

1. Murray $\mathrm{CJ}$ and Lopez AD. Measuring the global burden of disease. N Engl J Med 2013; 369(5); 448-459.

https://doi.org/10.1056/NEJMra1201534

2. Joshi $P$, Islam $S$ and Pais P. Risk Factors for Early Myocardial Infarction in South Asians Compared With Individuals in Other Countries. JAMA. 2007; 297(3):286-294.

https://doi.org/10.1001/jama.297.3.286 
3. Klein LW, Agarwal JB, Herlich MB, Leary TM and Helfant RH. Prognosis of symptomatic coronary artery disease in young adults aged 40 years or less. The American journal of cardiology. 1987; 60(16):1269-1272.

https://doi.org/10.1016/0002-9149(87)90606-0

4. Egred M, Viswanathan $\mathrm{G}$ and Davis GK. Myocardial infarction in young adults. Post grad Med J. 2005; 81(962):741-745. https://doi.org/10.1136/pgmj.2004.027532

5. Khot UN, Khot MB, Bajzer CT, Sapp SK, Ohman EM, Brener SJ, et al. Prevalence of conventional risk factors in patients with coronary heart disease. JAMA. 2003; 290:898-904. https://doi.org/10.1001/jama.290.7.898

6. Alizadehas $A$, Sepasi $F$ and Toufan M. Risk factors, clinical manifestations and outcome of acute myocardial infarction in young patients. J Cardiovasc Thorac Res 2010; 2(1):29-34.

7. Tamrakar R, Bhatt YD, Kansakar S, Bhattarai M, Shaha KB and Tuladhar E. Acute myocardial infarction in young adults: study of risk factors, angiographic features and clinical outcome. Nepalese Heart Journal. 2013; 10(1):12-16.

https://doi.org/10.3126/njh.v10i1.9740

8. Noor L, Adnan Y, Ali U, Dar MH, Uddin S, Ahmad F, et al. Characteristics of the coronary arterial lesions in young patients (<35 years) with Acute Myocardial Infarction. Pakistan Heart Journal. 2018; 50(4).

9. Chen L, Chester $M$ and Kaski JC. Clinical factors and angiographic features associated with premature coronary artery disease. Chest. 1995; 108(2):364-369.

https://doi.org/10.1378/chest.108.2.364

10. Saghir T, Qamar N and Sial J. Coronary angiographic characteristics of coronary artery disease in young adults under age forty years compare to those over age forty. Pakistan Heart Journal. 2012; 41(3-4).

11. Ahmad T, Alam MB, Khan A, Islam AM, Hossain $Z$ and Asaduzzaman K. Study on Risk Factors and Pattern of Coronary Artery Involvement in Young Acute Coronary Syndrome Patients. Bangladesh Heart Journal. 2017; 32(1):40-44. https://doi.org/10.3329/bhj.v32i1.34169

12. Adhikari CM, Rajbhandari R, Limbu YR, Malla R, Sharma R, Rauniyar B, et al. A study on major cardiovascular risk factors in Acute Coronary Syndrome (ACS) patient 40 years and below admitted in CCU of Shahid Gangalal National Heart Center. Nepalese Heart Journal. 2010; 7(1):20-24. https://doi.org/10.3126/njh.v7i1.8497

13. Hong MK, Cho SY, Hong BK, Chang KJ, Chung IM, Lee MH, et al. Acute myocardial infarction in the young adults. Yonsei Medical Journal. 1994; 35(2):184-189.

https://doi.org/10.3349/ymj.1994.35.2.184

14. Welch CC, Proudfit WL, Sones Jr FM, Shirey EK, Sheldon WC and Razavi M. Coronary arteriography in young men. Circulation. 1970; 42(4):647-652.

https://doi.org/10.1161/01.CIR.42.4.647

15. Siddiqui NM, Bhatti KI, Farman MT and Khan NU. Frequency of risk factors in patients presenting with Acute Coronary Syndrome below 40 years of age. Pakistan Heart Journal. 2019; 52(3).

16. Navas-Nacher EL, Colangelo L, Beam $C$ and Greenland P. Risk factors for coronary heart disease in men 18 to 39 years of age. Annals of Internal Medicine. 2001; 134(6):433-439. https://doi.org/10.7326/0003-4819-134-6-200103200-00007.

\footnotetext{
Author's contributions:

BKR-Concept and design of the study, manuscript preparation, statistically analyzed and interpreted, Critical revision of the manuscript; AK- Concept and design of the study, critical revision of manuscript and review of the study; KPA-Reviewed the literature, helped in preparing first draft of manuscript, collected data; KT- Collected data, statistically analyzed and interpreted, helped in preparing first draft of manuscript; RBA- Reviewed the literature, helped in preparing first draft of manuscript; DL-Reviewed the literature, helped in preparing first draft of manuscript; SRB-Concept and design of the study, critical revision of manuscript and review of the study; SBK- Concept and design of the study, critical revision of manuscript and review of the study; CMA- Concept and design of the study, critical revision of manuscript and review of the study; AM- Concept and design of the study, critical revision of manuscript and review of the study; RRB-Concept and design of the study, critical revision of manuscript and review of the study; RM- Collected data, statistically analyzed and interpreted, helped in preparing first draft of manuscript.

Work attributed to:

Department of Cardiology, Shahid Gangalal National Heart Centre, Kathmandu, Nepal.

Orcid ID:

Dr. Binay Kumar Rauniyar - (D https://orcid.org/0000-0003-0466-1052

Dr. Arun Kadel - (i) https://orcid.org/0000-0002-7782-9445

Dr. Kiran Prasad Acharya - (D) https://orcid.org/0000-0003-2765-4242

Dr. Chandra Mani Adhikari - (D) https://orcid.org/0000-0001-5811-9977

Sources of support: None, Conflicts of Interests: None.
} 